to our patients in such a way that they are fully understood.

What I wish to add is that the doctor, if he is to show the sensitivity needed under the circumstances, must himself have confronted, and worked through in his imagination, the despair, fear, and grief, of his own future death - and as a result to have achieved equanimity in the face of this universal reality.

U. B. H. BARUCH

2 Queen's Walk, Ealing, London W5 1TP

\section{The integration of psychiatry and peychotherapy}

Sir: We were delighted to read Jeremy Holmes optimistic editorial (Psychiatric Bulletin, August 1995, 19, 465-466) regarding the integration of the specialities of psychiatry and psychotherapy. However, a major omission was the thorny issue of training. Why does an organisation like the NHS specify the need for psychoanalytic and other psychotherapies, yet not accept any responsibility for comprehensive training?

It is specifically to avoid delivering care in a 'vaguely psychodynamic' and possibly harmful way that many junior doctors seek a systematic training in psychoanalytic individual, group, or family psychotherapy at their own expense. The Royal College of Psychiatrists (Grant et al, 1993) states that experience in individual dynamic psychotherapy is a mandatory requirement for qualification, and acknowledges the "danger of the devaluation of the need for rigorous training". A recognition of the sparse supervision available within the NHS, and work demanding a high level of therapeutic skill, fuel the wish to be properly trained, even if one does have to fund it oneself and accommodate the training around ones' fulltime NHS job. Private training organisations' fees and training analyses can cost up to $£ 15-30000$ over several years. Many would deem anyone taking on such training at personal cost as misguided; yet we believe that many trainees see themselves as having little choice. Additionally. doctors are disadvantaged compared to nonmedical colleagues in attempting to recoup their training expenditure by practising privately, not being allowed to advertise or have a listing on registers which are available to the public (British Medical Association, 1991).

It has been said that in the United States "psychotherapy is rapidly becoming an endangered species" (Wallerstein, 1991) due to a reduction in core junior doctor psychotherapeutic training. Here in the UK, the reality of limited funding must encourage the split that Holmes describes. This split strengthens the identity of each discipline at the expense of mutually beneficial working arrangements. Joint training arrangements could serve as a focus of increasing cooperation, yet there is little comment on how to facilitate comprehenstve training within the NHS and for the benefit of NHS patients.

BRTTSH MEDICAL ASSOCIATON (1991) Guidelines to Doctors on Advertising. London: BMA.

GRANT, S., HoLmES, J. \& WATSON, J. (1993) Guidelines for psychotherapy training as part of general professional psychiatric training. Psychiatric Bulletin, 17, 695-698.

WALLERSTEIN. R. S. (1991) The future of psychotherapy. Bulletin of the Menninger Clinic, 65, 421-443.

K. BHUl and A. AUBIN

The Maudsley Hospital, London SE5 8AZ

Sir: Dr Jeremy Holmes has cited me inaccurately (Psychiatric Bulletin. August 1995, 19, 465) in writing that "Marks now concedes that psychoanalytic psychotherapy has a role in the longterm treatment of patients with personality disorder".

The passage referred to (British Medical Journal, 309, 1072) in fact read: "It would be justifiable to give some patients with chronic personality problems prolonged psychotherapy in the NHS if benefit from it is shown and there are no good brief alternatives. Unless value is proved, however, prolonged treatment should not be part of routine care." A different meaning somehow.

ISAAC MARKS

Professor of Experimental Psychopathology. Institute of Psychiatry.

De Crespigny Park, London SE5 8AF

\section{Reducing non-attendence at out-patient clinics}

Sir: Rusius (Psychiatric Bulletin, May 1995, 19. 291-292) rightly emphasises the costly nature of non-attendance at out-patient clinics. An alternative method of reducing non-attendance is to visit the patient at home.

For a four year period (1989-1992) one of us (DA) prospectively studied a domiciliary clinic in an old age psychiatric service. All new out-patient referrals were seen in their own home for initial assessment. Non-attendance rates were compared with a traditional hospital clinic run by the second consultant in the department. Nonattendance rate for the domiciliary clinic was $1.7 \%$ (8 of 462 referrals) and the hospital clinic $21.2 \%$ (57 of 269 referrals). Non-attendance for 
the domiciliary clinic was a failed patient contact when attending the home.

Of course, the elderly and general adult populations are not necessarily comparable. One of us (DL) subsequently piloted a similar domiciliary clinic for the 16-64 years age group specifically because the non-attendance rate for new referrals to the hospital clinic over the previous six months was $53 \%$. For the following six months, new out-patient referrals who would have been seen in the hospital clinic were visited at home. The non-attendance rate fell to $15 \%$.

It appears that visiting patients at home is another effective method of reducing non-attendance and has the advantage that the psychiatrist can directly observe the patient's home circumstances. From an efficiency point of view the limiting factor is time spent travelling to patients' homes and efficiency savings may not be realised where distances are large. The services described are inner city and adjacent districts of Liverpool that may be similar to the Sheffield service described by Rusius, who notes that the average distance between patients' home and hospital was only 3.7 miles. The average distance travelled in the elderly domiciliary clinic was 12.6 miles per clinic seeing an average 2.7 patients per clinic.

Experience indicates that patients like the domiciliary arrangements. Jones et al (1987) found that $72 \%$ of new general adult psychiatric referrals stated a preference for home visiting and only $12 \%$ for out-patients or general practice clinic. Eighty per cent felt assessors had gained a better idea of their difficulties because they were seen at home.

JONES, S. J., TURNER, R. J. \& GRANT J. E. (1987) Assessing patients in their own homes. Psychiatric Bulletin, 11. 117-119.

DAVID N. ANDERSON and DAVID $L$ EMI Directorate, Sir Douglas Crawford Unit, Mossley Hill Hospital, Park Avenue, Liverpool L18 8BU

\section{Progress in defeating depression}

Sir: I note that one of the tasks of the Defeat Depression campaign as described by Priest et al (Psychiatric Bulletin, August 1995, 19, 491-495) is public education, and that $90 \%$ of their sample "thought that depressed patients should be offered counselling." It is not clear from the discussion that follows whether they regard this as evidence of ignorance or as a valid request for services for depressed people.

\section{Sebastian KRaEmer}

Child and Family Psychiatric Service,

The Whittington Hospital, F Block,

Highgate Hill, London N19 5NF

Sir: The answer to Dr Kraemer's question is found in the consensus statement on which the Campaign is based (Paykel \& Priest, 1992). Psychological (non-drug) treatments have an important place in the armamentarium of treatments that we propose for depression. Cognittve therapy in particular deserves attention.

We did not regard the attitude revealed in this answer as worrying. What did concern us, however, was that the majority of respondents regarded antidepressants as addicting. I am pleased to say that there has been a significant improvement in this answer in a more recent survey. Nevertheless, it is probably still the case that, where the patient and the doctor agree that a course of antidepressants is called for, the doctor should make it very clear to the patient that addiction is not a problem with antidepressants. Non-compliance is a serious hazard when medication is prescribed for depression, and many patients probably give up their antidepressant prematurely because they are afraid of becoming dependent on it.

\section{PAyKrL, E. S. \& PrIEst, R. G. (1992) Recognition and management of depression in general practice: consensus statement. British Medical Journal, s06. 1198-1202.}

R. G. PRIEST

Chairman, Defeat Depression Campaign

\section{Sexism or pragmatism?}

Sir: We read with interest the article by Hall and Deahl on the inadequacies of history taking by trainee psychiatrists in casualty (Psychiatric Bulletin, September 1995, 19, 538-540). While we agree that efforts are merited to increase alcohol and substance abuse histories in all groups, we disagree that this discrepancy is likely to represent ageist or sexist attitudes. The OPCS survey (Goddard, 1991) of drinking habits in the late 1980s (quoted in part in Hall \& Deahl's article), found that $23 \%$ of men and $8 \%$ of women exceeded sensible drinking levels (21 units for men and 14 units for women). Excess drinking showed a decline with increasing age in both sexes. Based on these flgures, if a full alcohol history had been taken in all cases at least a further $5.3 \%$ of men and $3.4 \%$ of women would have been identified as exceeding sensible drinking levels. The recording of disorders more likely 